\title{
Gas/particle partitioning of carbonyls in the photooxidation of isoprene and 1,3,5-trimethylbenzene
}

\author{
R. M. Healy ${ }^{1}$, J. C. Wenger ${ }^{1}$, A. Metzger ${ }^{2}$, J. Duplissy ${ }^{2}$, M. Kalberer ${ }^{3}$, and J. Dommen ${ }^{2}$ \\ ${ }^{1}$ Department of Chemistry and Environmental Research Institute, University College Cork, Cork, Ireland \\ ${ }^{2}$ Laboratory of Atmospheric Chemistry, Paul Scherrer Institut, 5232 Villigen, Switzerland \\ ${ }^{3}$ Department of Chemistry and Applied Biosciences, ETH Zurich, 8093 Zurich, Switzerland
}

Received: 11 January 2008 - Published in Atmos. Chem. Phys. Discuss.: 5 March 2008

Revised: 26 May 2008 - Accepted: 30 May 2008 - Published: 26 June 2008

\begin{abstract}
A new denuder-filter sampling technique has been used to investigate the gas/particle partitioning behaviour of the carbonyl products from the photooxidation of isoprene and 1,3,5-trimethylbenzene. A series of experiments was performed in two atmospheric simulation chambers at atmospheric pressure and ambient temperature in the presence of $\mathrm{NO}_{\mathrm{x}}$ and at a relative humidity of approximately $50 \%$. The denuder and filter were both coated with the derivatizing agent $O$-(2,3,4,5,6-pentafluorobenzyl)-hydroxylamine (PFBHA) to enable the efficient collection of gas- and particlephase carbonyls respectively. The tubes and filters were extracted and carbonyls identified as their oxime derivatives by GC-MS. The carbonyl products identified in the experiments accounted for around 5\% and $10 \%$ of the mass of secondary organic aerosol formed from the photooxidation of isoprene and 1,3,5-trimethylbenzene respectively.

Experimental gas/particle partitioning coefficients were determined for a wide range of carbonyl products formed from the photooxidation of isoprene and 1,3,5trimethylbenzene and compared with the theoretical values based on standard absorptive partitioning theory. Photooxidation products with a single carbonyl moiety were not observed in the particle phase, but dicarbonyls, and in particular, glyoxal and methylglyoxal, exhibited gas/particle partitioning coefficients several orders of magnitude higher than expected theoretically. These findings support the importance of heterogeneous and particle-phase chemical reactions for SOA formation and growth during the atmospheric degradation of anthropogenic and biogenic hydrocarbons.
\end{abstract}

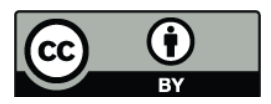

Correspondence to: J. C. Wenger (j.wenger@ucc.ie)

\section{Introduction}

The atmospheric degradation of volatile organic compounds (VOCs) yields a range of oxygenated products that, depending on their physical and chemical properties, can lead to the formation of secondary organic aerosol (SOA). There is considerable interest in SOA because it accounts for a significant fraction (up to 80\%) of ambient atmospheric aerosol and can therefore affect climate and human health (Pöschl, 2005). Despite extensive efforts over recent years, there remain uncertainties in the environmental impact of SOA, because of a lack of knowledge on the sources, composition, properties and mechanisms for its formation (Fuzzi et al., 2006).

Biogenic and anthropogenic sources of VOCs both contribute to SOA formation. Until very recently the major biogenic SOA precursors were believed to be the terpenes and sequiterpenes. However, the importance of isoprene as a biogenic SOA precursor has been confirmed in a number of recent field and laboratory experiments (Claeys et al., 2004; Dommen et al., 2006; Edney et al., 2005; Kleindienst et al., 2006; Kroll et al., 2005a; Kroll et al., 2006; Surratt et al., 2006; Szmigielski et al., 2007). Whilst biogenic VOCs are the dominant contributors to global SOA formation, anthropogenic species such as the aromatic compounds (benzene, toluene, xylenes and trimethylbenzenes) can contribute significantly to the production of SOA in urban areas (Kanakidou et al., 2005). A considerable amount of information on the SOA-forming potential of individual biogenic and anthropogenic VOCs has been obtained from simulation chamber experiments performed over the last 10 years (Kroll et al., 2006; Ng et al., 2007; Odum et al., 1997). However, elucidation of the processes and chemical species responsible for SOA formation has proven more difficult. Although a number of recent studies have utilised state-of-the-art methods to investigate the chemical composition of SOA, in general the overall yield of products detected in the particle phase

Published by Copernicus Publications on behalf of the European Geosciences Union. 
Table 1. Starting concentrations and results for the isoprene (ISO) and 1,3,5-trimethylbenzene (TMB) photooxidation experiments performed at a relative humidity of approximately $50 \%$.

\begin{tabular}{lcccccc}
\hline Experiment & $\begin{array}{c}{[\mathrm{HC}]_{0}} \\
(\mathrm{ppbV})\end{array}$ & $\begin{array}{c}{[\mathrm{NO}]_{0}} \\
(\mathrm{ppbV})\end{array}$ & $\begin{array}{c}{\left[\mathrm{NO}_{2}\right]_{0}} \\
(\mathrm{ppbV})\end{array}$ & $\begin{array}{c}\Delta[\mathrm{HC}]^{\mathrm{a}} \\
\left(\mu \mathrm{g} \mathrm{m}^{-3}\right)\end{array}$ & $\begin{array}{c}\text { Aerosol Mass }^{\mathrm{b}} \\
\left(\mu \mathrm{g} \mathrm{m}^{-3}\right)\end{array}$ & $\begin{array}{c}\text { Aerosol Yield } \\
(\%)\end{array}$ \\
\hline ISO_PSI_1 & 1776 & 446 & 488 & 4283 & 203 & 4.72 \\
ISO_PSI_2 & 1473 & 344 & 365 & 3959 & 189 & 4.76 \\
ISO_UCC_1 & 2011 & 390 & 106 & 5140 & 220 & 4.29 \\
ISO_UCC_2 & 4079 & 686 & 269 & 10541 & 467 & 4.43 \\
TMB_PSI_1 & 815 & 194 & 177 & 1822 & 110 & 6.01 \\
TMB_PSI_2 & 1027 & 335 & 289 & 2488 & 208 & 8.34 \\
TMB_PSI_3 & 1017 & 286 & 294 & 2673 & 195 & 7.28 \\
TMB_UCC_1 & 1193 & 246 & 21 & 3137 & 141 & 4.50 \\
TMB_UCC_2 & 2929 & 496 & 100 & 7039 & 359 & 5.10 \\
\hline
\end{tabular}

a Amount of parent hydrocarbon (HC) reacted, corrected for dilution due to sampling.

$\mathrm{b}$ Determined at the time of measured maximum particle volume concentration, corrected for wall loss, assuming a density of $1.4 \mathrm{~g} \mathrm{~cm}{ }^{-3}$.

${ }^{\mathrm{c}}$ Calculated from aerosol mass/ $\Delta[\mathrm{HC}]$.

is typically less than 30\% (Forstner et al., 1997; Hamilton et al., 2005). Some of the species detected in SOA are first generation oxidation products that have partitioned into the particle phase, while others are formed through further gas-phase oxidation of the products followed by partitioning (Jang and Kamens, 2001). In addition, the identification of oligomers and oligoesters in SOA has added further complexity to the overall mechanistic picture of SOA formation and indicates that heterogeneous and particle-phase reactions may also play an important role (Dommen et al., 2006; Kalberer et al., 2004; Surratt et al., 2006; Szmigielski et al., 2007).

Clearly more information is required to improve our understanding of SOA formation. An important piece of information that is often missing from chamber experiments is knowledge of the gas/particle partitioning of the VOC oxidation products, which can be particularly useful in determining the specific oxidation products involved in SOA formation. However, experimentally determined gas/particle partitioning coefficients of oxidation products have only been reported for a limited number of biogenic SOA precursors, such as $\alpha$-pinene and other monoterpenes (Yu et al., 1999), and toluene as the only anthropogenic SOA precursor (Jang and Kamens, 2001). The objective of this work was to use a recently developed denuder-filter system (Temime et al., 2007) to investigate the gas/particle partitioning of the carbonyl photooxidation products of isoprene and 1,3,5-trimethylbenzene (1,3,5-TMB). Experiments were carried out in simulation chambers at the Paul Scherrer Institut (PSI) and University College Cork (UCC) for intercomparison purposes. The results are used to determine experimental gas/particle partitioning coefficients and to provide insights into the oxidation products involved in SOA formation, along with their contribution to the chemical composition of the particle phase.

\section{Experimental}

\subsection{PSI experiments}

The simulation chamber at PSI has been used for several photooxidation studies and is described in detail elsewhere (Paulsen et al., 2005). Briefly, the apparatus consists of a cubic $27 \mathrm{~m}^{3}$ FEP Teflon foil chamber housed in a wooden temperature-controlled enclosure. The walls and ceiling of the enclosure are covered with aluminium foil to maximize light intensity and diffusion. Light is provided by four xenon arc lamps ( $4 \mathrm{~kW}$, XPO $4000 \mathrm{~W} / \mathrm{HS}$, OSRAM), with one in each corner of the enclosure. Borosilicate filters are located in front of each lamp to reduce actinic UV radiation below $300 \mathrm{~nm}$.

Five photooxidation experiments were performed in the PSI chamber. The initial starting conditions for the experiments are given in Table 1. All experiments were carried out at a relative humidity of approximately $50 \%$, a temperature of $293 \mathrm{~K}$, and atmospheric pressure in the absence of seed aerosol. For each experiment the chamber was first humidified, followed by the introduction of $\mathrm{NO}$ and $\mathrm{NO}_{2}$. Finally, known amounts of either isoprene or 1,3,5-TMB were evaporated in a heated glass bulb and introduced in a flow of purified air. The mixture was allowed to mix for $30 \mathrm{~min}$ before turning on the lights. Parent hydrocarbons and photooxidation products were monitored using proton-transfer mass spectrometry (PTR-MS) (Ionicon Analytik GmbH). Ozone was measured using a commercial Environics S300 instrument, whilst $\mathrm{NO}$ and $\mathrm{NO}_{2}$ were quantified using a Thermo Environmental Instruments (42C) analyzer equipped with a photolytic converter to selectively reduce $\mathrm{NO}_{2}$ to NO. Particle size distributions (14-964 nm in diameter) were measured with a scanning mobility particle sizer and a TSI 3010 condensation particle counter. 
The gas- and particle-phase carbonyl oxidation products generated in the photooxidation experiments were separated and simultaneously collected using a denuder-filter sampling device recently developed at UCC (Temime et al., 2007). It consists of an annular denuder coated with XAD-4 resin and the derivatizing agent $O$-(2,3,4,5,6-pentafluorobenzyl)hydroxylamine (PFBHA), to enable on-tube conversion of gas-phase carbonyls to their oxime derivatives which can be extracted and identified by GC-MS. The filter is also doped with PFBHA to enable detection of particle-phase carbonyls by GC-MS. A second denuder tube is located downstream of the filter to trap any particle phase species that might revert to the gas phase during sampling. A schematic diagram of this denuder-filter-denuder (D-F-D) configuration is shown in Fig. 1.

The concentrations of the carbonyls produced in these photooxidation experiments were considerably smaller than those used in the original tests of the denuder performance (Temime et al., 2007). As a result, the amount of PFBHA used for coating the denuder tubes was reduced by a factor of four (to $0.02 \mathrm{~g}$ ), while the filters were doped with $0.002 \mathrm{~g}$ of PFBHA. The use of a lower amount of PFBHA prompted another series of tests to ensure efficient collection of the gasphase carbonyls. In order to determine the collection efficiency, an alternative sampling configuration, consisting of a filter-denuder-denuder (F-D-D), was employed as shown in Fig. 1. A second method to test the collection efficiency of the denuder was also performed. This involved placing the PTR-MS inlet at the entrance and exit of a coated denuder tube while the reaction mixture from the chamber was pumped through the denuder at $10 \mathrm{~L} \mathrm{~min}^{-1}$. Thus the breakthrough of gas-phase products was measured in real time and an optimum sampling duration was evaluated.

The denuder-filter apparatus was located inside the temperature-controlled chamber housing in order to avoid a temperature gradient during sampling which could affect gas/particle partitioning of the photooxidation products. Based on the collection efficiency results a sampling duration of $50 \mathrm{~min}$ was chosen with a flow of $10 \mathrm{~L} \mathrm{~min}^{-1}$. Denuder-filter samples were taken at regular intervals during each experiment using both the D-F-D and F-D-D configurations. The denuder tubes were coated by adding a slurry of finely ground XAD- 4 resin $(0.40 \mathrm{~g})$ in $10 \mathrm{~mL}$-hexane to the denuder, closing the end caps and rotating the tube along its axis and inverting the ends several times. The excess slurry was then poured out, the tube was dried using purified air, and these steps were repeated until all of the resin was sorbed on the denuder walls. The PFBHA $(0.02 \mathrm{~g}$ in $5 \mathrm{~mL}$ methanol) was then added to the tube and dried in the same way. The filters (Pallflex Fiberfilm fluorocarboncovered glass fibre filters, $47 \mathrm{~mm}$ ) were doped with PFBHA by applying a solution $(0.002 \mathrm{~g}$ in $350 \mu \mathrm{L}$ methanol and $60 \mu \mathrm{L}$ Milli-Q water) directly to the filter surface followed by drying with purified air. The tubes and filters were extracted immediately after sampling using a solvent mix-

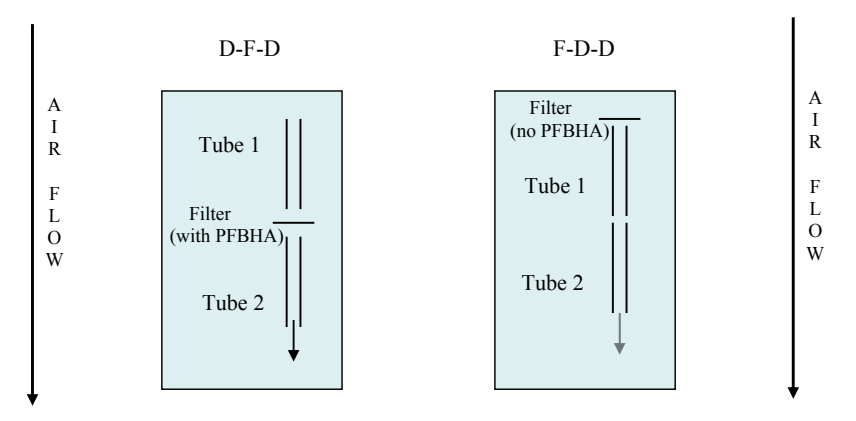

Fig. 1. The denuder-filter-denuder (D-F-D) and filter-denuderdenuder (F-D-D) sampling configurations used for determining gas/particle partitioning and gas-phase breakthrough respectively.

ture (methanol/dichloromethane/acetonitrile $0.5 / 8.5 / 1 \mathrm{v} / \mathrm{v} / \mathrm{v}$ ) ( $20 \mathrm{~mL}$ per tube and $10 \mathrm{~mL}$ per filter). For the denuders this involved inverting the tube several times and pouring out the extract into a round-bottomed flask. The filters were simply placed in a round-bottomed flask and immersed in the extraction solvent. The extracts were stored in the dark at room temperature overnight and then reduced to a known volume (approximately one third of the original volume) by rotary evaporation, filtered using a PTFE membrane filter (pore size $0.45 \mu \mathrm{m}$ ), transferred to vials and shipped to UCC for GCMS analysis. Blank denuder and filter samples were prepared and extracted in the same way.

\subsection{UCC experiments}

Photooxidation of isoprene and 1,3,5-TMB was also performed in the simulation chamber at UCC in order to compare aerosol yields and partitioning data for the oxidation products formed in the two chambers. The UCC chamber is described in detail elsewhere (Temime et al., 2007). Briefly, the chamber is rectangular, made of FEP Teflon foil, has a volume of ca. 6500 litres and is surrounded by 12 Philips TL12 (40 W) lamps with an emission maximum at $310 \mathrm{~nm}$ and 12 Philips TL05 $(40 \mathrm{~W})$ lamps with an emission maximum at $360 \mathrm{~nm}$.

Four photooxidation experiments were performed in the UCC chamber. A summary of the initial starting conditions for the experiments is given in Table 1. The chamber does not have any cooling system and the temperature gradually increased during the experiments from 293 to around $305 \mathrm{~K}$. The initial relative humidity was approximately $50 \%$ in each case. No seed aerosol was used. The chamber was humidified by flowing purified air through the headspace of an impinger containing boiling distilled water. Isoprene and 1,3,5TMB were also introduced through a heated impinger and concentrations were monitored by GC-FID. $\mathrm{NO}$ and $\mathrm{NO}_{\mathrm{x}}$ concentrations were measured with a chemiluminescence $\mathrm{NO}_{\mathrm{x}}$ analyzer (Thermo Model 42i) and ozone was measured with a UV photometric $\mathrm{O}_{3}$ analyzer (Thermo Model 49i). 
The formation and evolution of particles in the range 10 $470 \mathrm{~nm}$ was monitored using a scanning mobility particle sizer (SMPS, TSI Model 3034).

Denuder-filter sampling in the UCC experiments was performed in the same manner as outlined above but with the sampling time reduced to 20 min because of the smaller volume of the chamber. Once the particle mass had reached a maximum in each experiment, three denuder-filter samples were taken. Temperatures were in the range 303$305 \mathrm{~K}$ during sampling. The solvent mixture for extraction of the denuder contents was replaced with methanol as dichloromethane was found to degrade the glue holding the annular spaces of the denuder together over time, causing the tubes to eventually break. Due to the change in extraction solvent, a second extraction of each denuder tube was performed to ensure complete collection of the oxime derivatives. The efficiency of the first methanol extraction step was found to be greater than $90 \%$ for all species, showing a similar level of performance as the solvent mixture (Temime et al., 2007). For the sake of accuracy, the amounts measured in both extracts were combined for quantitative analyses of the denuder samples. A more efficient pre-concentration step was also employed which involved blowing down $1 \mathrm{~mL}$ of the filter extracts to near dryness at room temperature using nitrogen and reconstituting them with $100 \mu \mathrm{L}$ of methanol. These solutions were then transferred to conical vial inserts and analyzed by GC-MS. Blank denuders and filters were prepared in the same way and extracted. Standard solutions were also used to quantify the photooxidation products in the gas and particle phases. Structurally similar compounds were used for those carbonyls which were not readily available.

\subsection{GC-MS analysis}

Prior to GC-MS analysis, the denuder and filter extracts were left in the dark at room temperature for at least $72 \mathrm{~h}$ to ensure complete derivatization. A Varian ion trap GC-MS system (Saturn 2000) equipped with a split/splitless injector (Varian 1079) was used for chemical analysis. The chromatographic column used was a Chrompack CP-Sil-8CB, (5\% phenyl, 95\% dimethylpolysiloxane), $30 \mathrm{~m}$ in length, with an internal diameter of $0.25 \mathrm{~mm}$. The derivatives were analysed using the following column oven temperature program: $60^{\circ} \mathrm{C}$ held for $1 \mathrm{~min}$, then ramped from $60^{\circ} \mathrm{C}$ to $100^{\circ} \mathrm{C}$ at $5^{\circ} \mathrm{C} \mathrm{min}^{-1}$, from $100^{\circ} \mathrm{C}$ to $280^{\circ} \mathrm{C}$ at $10^{\circ} \mathrm{C} \mathrm{min}^{-1}$ and from $280^{\circ} \mathrm{C}$ to $310^{\circ} \mathrm{C}$ at $30^{\circ} \mathrm{C} \mathrm{min}^{-1}$. The temperature was then held for $5 \mathrm{~min}$. The injector temperature was held at $280^{\circ} \mathrm{C}$ for $1 \mathrm{~min}$ and then ramped to $310^{\circ} \mathrm{C}$ at $50^{\circ} \mathrm{C} \mathrm{min}{ }^{-1}$. EI mass spectra were acquired over a mass range $\mathrm{m} / \mathrm{z}, 60-650 \mathrm{amu}$. When analysing the PFBHA derivatives, reconstructed ion chromatograms were used. The $m / z=181$ ion EI fragment was used in most cases for quantification of the derivatized carbonyls. However reconstructed ion chromatograms with more specific EI fragments ions were used whenever coelution occurred.

\subsection{Materials}

The following compounds, with stated purities in brackets, were obtained from Sigma Aldrich Chemical Company; Amberlite XAD-4 resin, PFBHA ( $\geq 98 \%)$, methanol (99.9\%), dichloromethane ( $\geq 99.8 \%)$, acetonitrile (99.9\%), isoprene $(99 \%)$, methacrolein $(95 \%)$, methylvinylketone (99\%), valeraldehyde (97\%) glyoxal (40\% in water), methylglyoxal (40\% in water), 2,3-butanedione $(97 \%), 3,5-$ dimethylbenzaldehyde (97\%) and glyoxal trimer dihydrate ( $\geq 97 \%$ ). The following compounds, with stated purities in brackets, were obtained from Fluka; 1,3,5-trimethylbenzene (99\%), glycolaldehyde dimer (98\%), n-hexane ( $\geq 98 \%)$. The following compounds, with stated purities in brackets, were obtained from Lancaster Synthesis (UK); hydroxyacetone (95\%) and 2,5-hexanedione (97\%). Nitric oxide $(98.5 \%)$ was obtained from Sigma Aldrich Chemical Company.

\section{Results and discussion}

\subsection{Concentration-time profiles and aerosol yields}

The photooxidation of isoprene and 1,3,5-TMB was studied under a range of initial starting conditions, as indicated in Table 1. Typical concentration-time profiles obtained for experiments performed on isoprene and 1,3,5-TMB at PSI are shown in Figs. 2 and 3 respectively. The profiles for nitrogen oxides, ozone and particle mass were very similar in all experiments. As expected the decay of the hydrocarbon promotes the conversion of $\mathrm{NO}$ to $\mathrm{NO}_{2}$ and the subsequent formation of ozone. SOA formation was observed after 80-140 min and coincided with the point at which all NO had been converted to $\mathrm{NO}_{2}$. Following nucleation, the particles continued to grow due to condensation before reaching a maximum after about $300 \mathrm{~min}$ and then decreased due to wall losses. The particle mass was calculated from the measured volume concentration using a density of $1.4 \mathrm{~g} \mathrm{~cm}^{-3}$ which was determined by comparing the mobility diameter measurements from a differential mobility analyzer with the vacuum aerodynamic diameter measured with an online aerosol mass spectrometer (Dommen et al., 2006; Paulsen et al., 2005).

The formation of photooxidation products was monitored in real time using the PTR-MS, which detects VOCs in the form of the protonated molecular ion $(\mathrm{M}+1)$. In the isoprene experiments, the most abundant product ion appeared at $m / z=71$ and is attributed to the major first generation oxidation products, methacrolein (MACR) and methylvinylketone (MVK), which are isomers and cannot be distinguished in the PTR-MS. Additional major ions were also detected at the following $\mathrm{m} / \mathrm{z}$ values and are tentatively attributed to the corresponding secondary products arising from further oxidation of MACR and MVK; 61 (glycolaldehyde), 75 (hydroxyacetone), 59 (glyoxal) and 73 (methylglyoxal). All of 

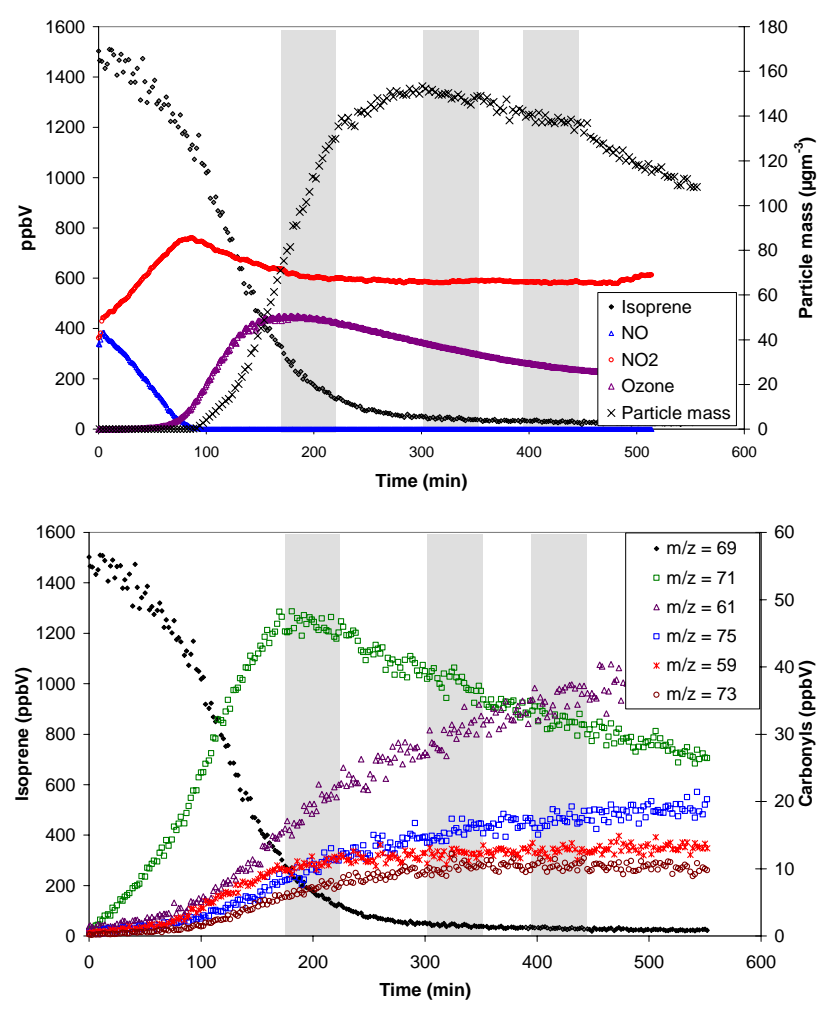

Fig. 2. Top: Concentration-time profile of isoprene, nitrogen oxides, ozone and particle mass for ISO_PSI_2. Bottom: PTR-MS concentration-time profile of masses corresponding to protonated isoprene and products for ISO_PSI_2. The grey areas represent the denuder-filter sampling periods.

these carbonyls have previously been identified as primary and secondary products of isoprene photooxidation (Carter, 1996; Yu et al., 1995) and are consistent with the current understanding of the atmospheric degradation mechanism. In the 1,3,5-TMB experiments, the major product ion appeared at $m / z=113$ and could be due to any of the following species; cis/trans 2-methyl-4-oxo-2-pentenal, 3,5-dimethyl-5(2H)-2furanone, 3,5-dimethyl-3(2H)-2-furanone, 3-methyl-furan2,5-dione. 2-methyl-4-oxo-2-pentenal has been previously observed as a photooxidation product of 1,3,5-TMB (Smith et al., 1999) but contributions from the other isomers are also possible. The other major ions were detected at $m / z=59,73$, 135 and are attributed to the photooxidation products glyoxal, methylglyoxal, and 3,5-dimethylbenzaldehyde respectively. It should be noted that the PTR-MS instrument was calibrated using gas standards (Apel-Riemer Environmental Inc., Denver, CO) containing isoprene, methylvinylketone, methacrolein and 1,3,5-TMB and a total of 27 alcohols, ketones, and aldehydes. For compounds included in these standards an uncertainty of 5\% is attributed to the data. For all oxygenated compounds in the gas standard an average sensitivity with an uncertainty of $30 \%$ was derived and applied to the other measured compounds.
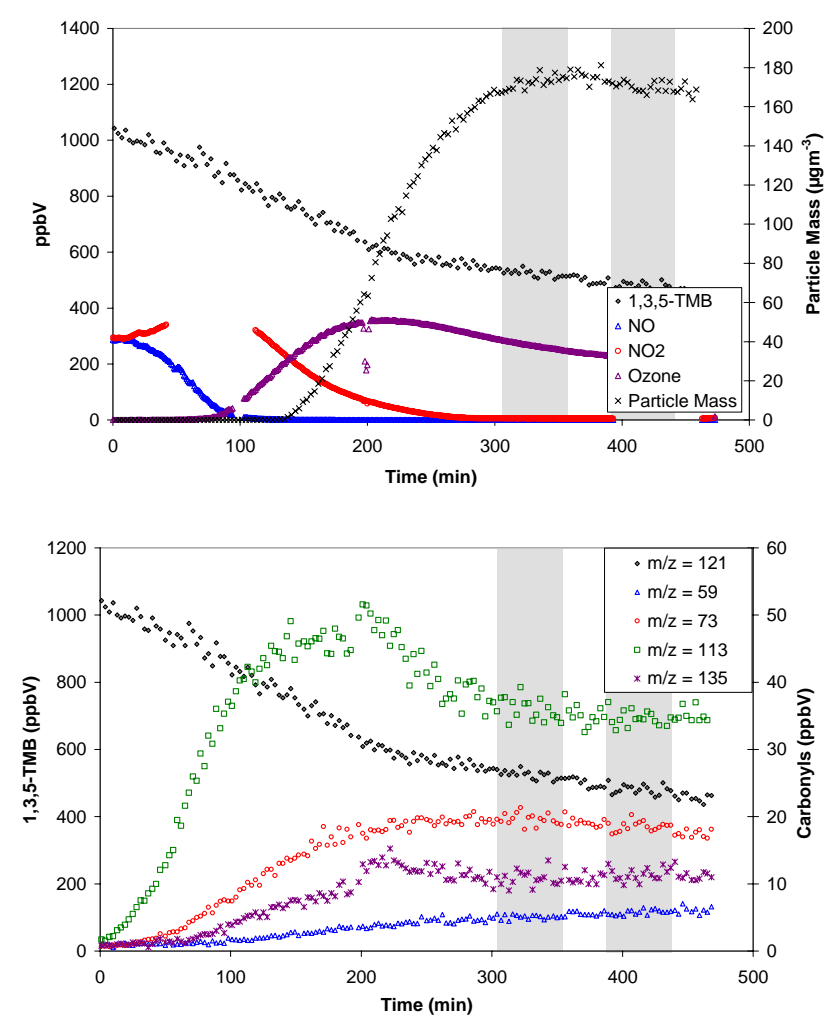

Fig. 3. Top: Concentration-time profile of 1,3,5-TMB, nitrogen oxides, ozone and particle mass for TMB_PSI_3. Bottom: PTR-MS concentration-time profile of masses corresponding to protonated 1,3,5-TMB and products for TMB_PSI_3. The grey areas represent the denuder-filter sampling period.

Similar concentration-time profiles for nitrogen oxides, ozone and particle mass were also obtained in the experiments performed at UCC, Fig. 4. However, the rate of decay of the parent hydrocarbons and NO was almost doubled and the formation of particles, which was still coincident with the point at which all $\mathrm{NO}$ had been converted to $\mathrm{NO}_{2}$, occurred earlier (after 30-45 $\mathrm{min}$ ) than in the experiments performed at PSI. The increased rate of reaction in the UCC chamber is due to the higher light intensity around $360 \mathrm{~nm}$ which results in an increased photolysis rate for the $\mathrm{OH}$ radical precursor HONO generated from the reaction of $\mathrm{NO}_{\mathrm{x}}$ at the walls of the reactor. It should also be noted that the wall loss rate of particles is higher in the UCC experiments due to the smaller volume to surface ratio in the chamber compared to PSI.

The yield of SOA produced in each experiment was calculated from the ratio of the aerosol mass formed to the amount of hydrocarbon reacted at the point where the maximum particle concentration was observed. The aerosol mass was corrected for wall losses by applying a first order loss rate obtained from the measured decay of the particles at the end of each experiment. The calculated yields are listed in Table 1 and, in general, show good agreement with previously reported SOA yields for these compounds (Cocker et al., 2001; 

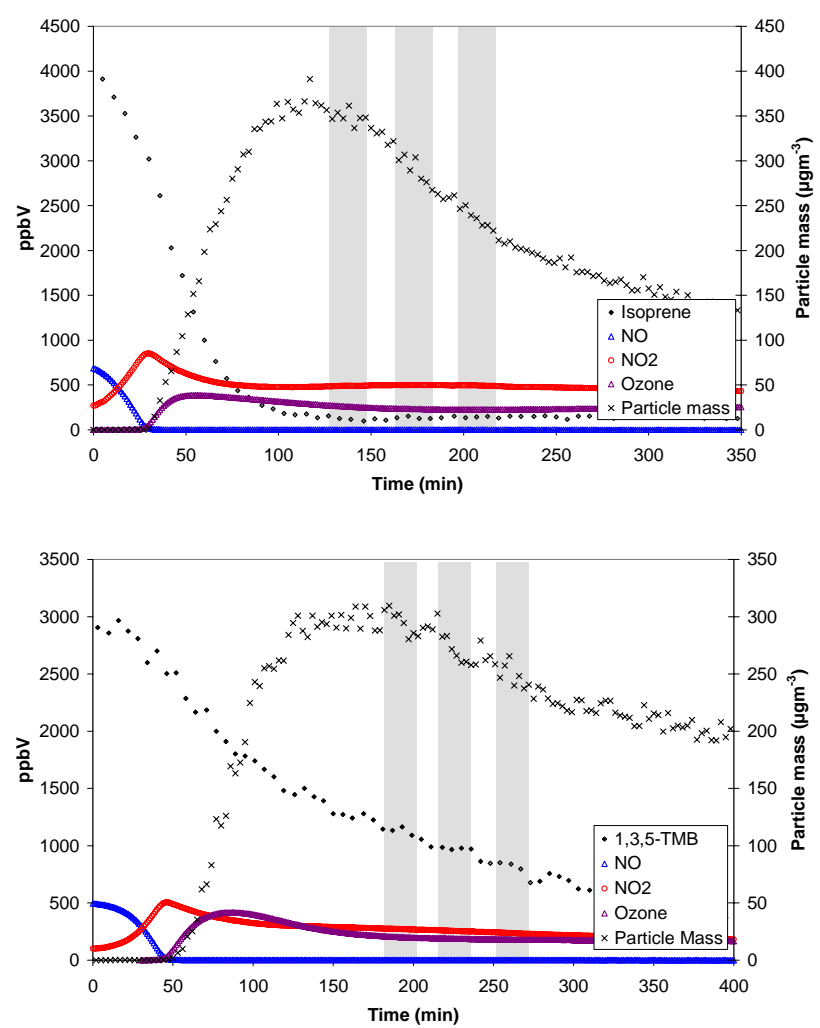

Fig. 4. Concentration-time profile of isoprene (top) and 1,3,5-TMB (bottom), nitrogen oxides, ozone and particle mass for ISO_UCC_2 and TMB_UCC_2. The grey areas represent the denuder-filter sampling period.

Dommen et al., 2006). However, it is apparent that the yields obtained at PSI, particularly for the 1,3,5-TMB experiments, are slightly higher than those obtained in the UCC chamber. There are a number of factors that affect the yield of SOA in simulation chamber experiments including temperature, humidity, seed aerosol and concentration of $\mathrm{NO}_{\mathrm{x}}$. In both chambers, the experiments were performed in the absence of seed aerosol, at a relative humidity of around $50 \%$ and under high- $\mathrm{NO}_{\mathrm{x}}$ conditions ( $>300 \mathrm{ppbV}$ ). For the experiments at PSI, the VOC to $\mathrm{NO}_{\mathrm{x}}$ ratio was approximately $2: 1$, with roughly equal parts of $\mathrm{NO}$ and $\mathrm{NO}_{2}$, whilst at $\mathrm{UCC}$ the $\mathrm{VOC} / \mathrm{NO}_{\mathrm{x}}$ ratio was around $4: 1$. The effect of $\mathrm{NO}_{\mathrm{x}}$ on SOA yields is a complex issue and has been discussed in detail for the photooxidation of isoprene (Kroll et al., 2006) and aromatics ( $\mathrm{Ng}$ et al., 2007). Although the total amount of $\mathrm{NO}_{\mathrm{x}}$ was varied to some extent, no clear relationship was observed between the mixing ratio of $\mathrm{NO}_{\mathrm{x}}$ and the SOA yield. This indicates that the variation in $\mathrm{NO}_{\mathrm{x}}$ concentrations employed during the set of experiments reported in this work was not sufficient to cause a significant change in the SOA yields. The most likely explanation for the higher SOA yields in the PSI experiments is the difference in temperature. The chamber at UCC does not have any cooling system and tem-
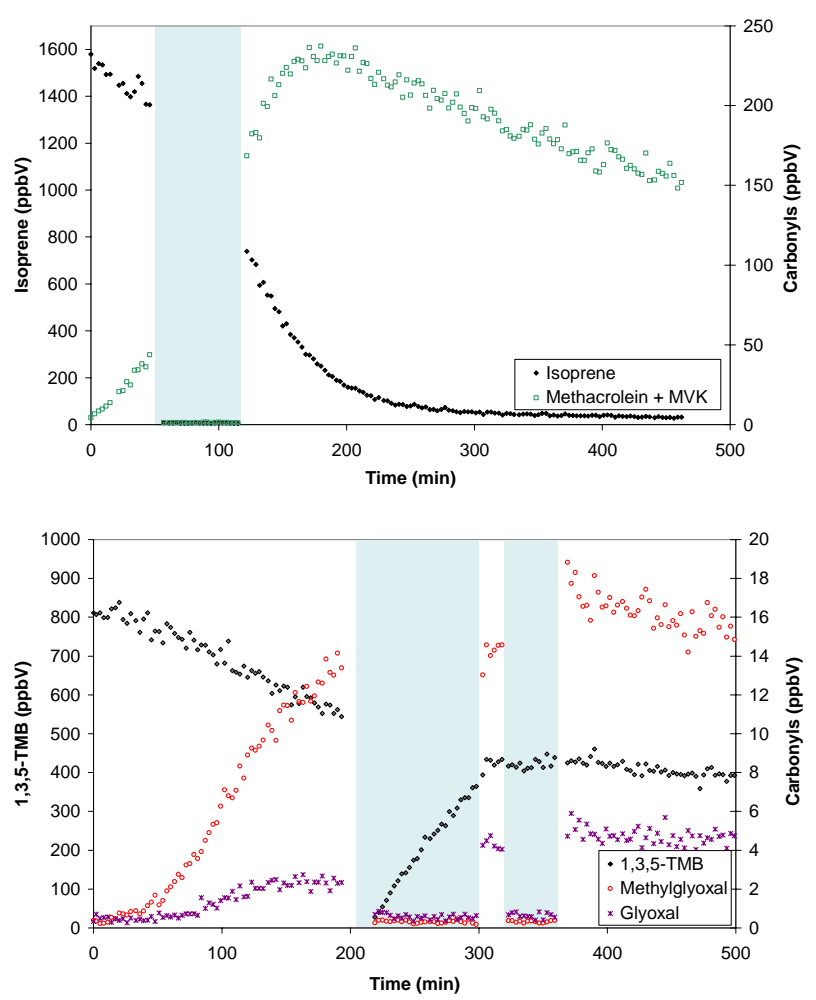

Fig. 5. PTR-MS Concentration-time profiles for isoprene, methacrolein and methylvinylketone (ISO_PSI_1), and 1,3,5-TMB, glyoxal and methylglyoxal (TMB_PSI_1). The shaded areas depict the periods when the PTR-MS sampled from the denuder tube exit.

peratures were in the range $303-305 \mathrm{~K}$ at maximum particle concentrations. At PSI experiments were carried out at $293 \mathrm{~K}$ and higher SOA yields may thus be expected due to more condensation of gas-phase products and thus addition of mass to the particle phase. It is interesting to note that this effect is more pronounced for 1,3,5-TMB, possibly indicating that the SOA contains more volatile species than those present in the SOA produced from isoprene photooxidation.

\subsection{Denuder collection efficiency}

The collection efficiency of the denuder was tested using the PTR-MS during the first isoprene (ISO_PSI_1) and 1,3,5TMB (TMB_PSI_1) photooxidation experiments. Figure 5 shows how the PTR-MS signal changed when a PFBHAcoated denuder tube was placed in front of the inlet whilst sampling from the chamber. For the isoprene system, MACR and MVK (as well as isoprene) were efficiently trapped by the denuder tube as indicated by the dramatic decrease of the corresponding PTR-MS signals as air was sampled from the exit of the denuder tube. After a sampling time of $60 \mathrm{~min}$ there was still no breakthrough observed, indicating that these compounds were effectively collected by the denuder throughout this period. For the 1,3,5-TMB system, both 


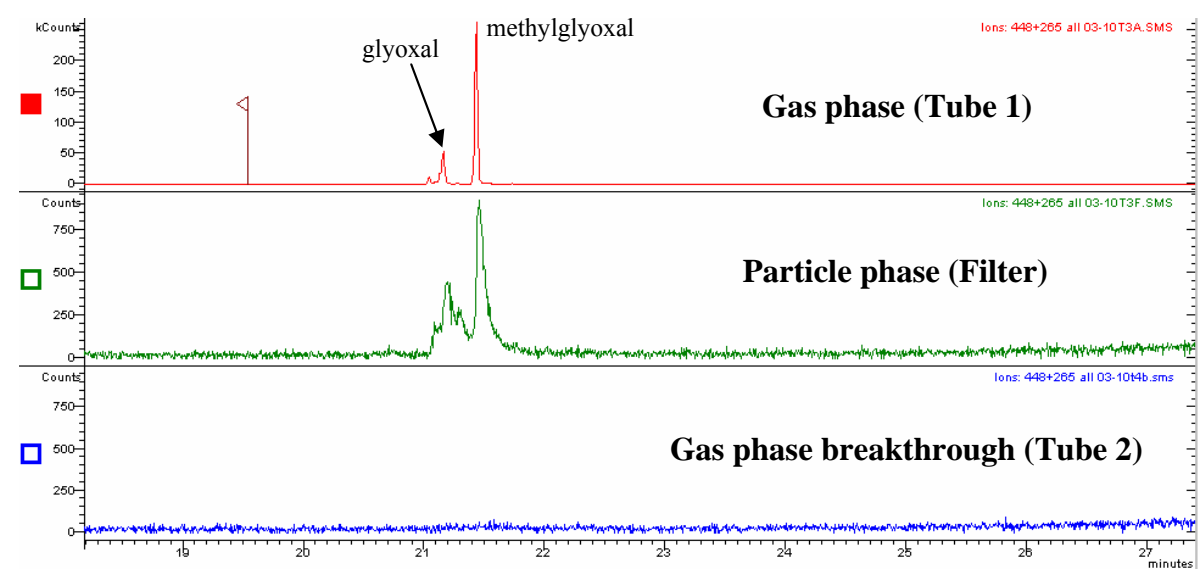

Fig. 6. Reconstructed ion chromatograms $(m / z=448+265)$ comparing the relative gas-phase, particle-phase and gas-phase breakthrough concentrations of glyoxal and methylglyoxal for ISO_PSI_1. The particle-phase and gas-phase breakthrough chromatograms are on the same scale.

glyoxal and methylglyoxal were efficiently trapped over a 150 min sampling period. Although the signal for 1,3,5-TMB initially dropped close to zero, it then gradually increased over this timeframe indicating that the denuder gradually became saturated with the parent VOC. It is important to note that even when breakthrough of 1,3,5-TMB was occurring, the signals for both glyoxal and methylglyoxal remained very close to zero indicating efficient collection of these carbonyls throughout the sampling period. Based on these results a sampling period of $50 \mathrm{~min}$ was chosen for the gas/particle partitioning studies in order to maximize the particle mass collected on the filter with minimal gas-phase breakthrough.

The potential artifacts arising from use of the D-F-D sampling configuration are (i) deposition of gas-phase species on the filter, leading to an overestimate of the particle-phase concentrations, and (ii) volatilisation of species from the filter, leading to an underestimate of the particle-phase concentrations. Deposition of gas-phase compounds to the filter can occur if the denuder collection efficiency is poor. The collection efficiency of the denuder tube was determined during each experiment at PSI using the F-D-D configuration, shown in Fig. 1. GC-MS data obtained for glyoxal and methylglyoxal in experiment ISO_PSI_1 are shown in Fig. 6. The results show that significant amounts of these dicarbonyls were collected on the filter and first denuder tube (Tube 1), while the amounts collected on Tube 2 were negligible. This confirms that gas-phase breakthrough of these compounds did not occur to any noticeable extent over a sampling period of $50 \mathrm{~min}$ and that the collection efficiency of the PFBHA-coated denuder tube was virtually $100 \%$ under the sampling conditions employed. Thus, potential artifacts due to deposition of gas-phase species on the filter were negligible. Volatilisation of species from the filter could occur as a result of a shift in the gas/particle partitioning equilibrium of the mixture following removal of the gas-phase species by the denuder. The D-F-D configuration was employed to account for this by using the second denuder to collect any volatilised particle-phase species. However, no significant amount of any carbonyl was observed on the second denuder tube, indicating that volatilisation is not an issue. This may simply be a result of the relatively short sampling times used in the experiments, but could also be due to the fact that the reaction of the carbonyls with PFBHA on the filter surface produces less volatile oximes, which subsequently remain sorbed.

\subsection{Identification of photooxidation products by GC-MS}

Denuder-filter sampling was employed 2-3 times during each experiment followed by GC-MS analysis of the denuder and filter extracts to identify carbonyl compounds present in the gas and particle phase respectively. Typical GC-MS data obtained from the photooxidation of isoprene and 1,3,5TMB are shown in Figs. 7 and 8. The carbonyl compounds were identified by the retention time and mass spectra of their oxime derivatives (Yu et al., 1995, 1997) and are listed in Tables 2 and 3. All of these carbonyls have previously been observed (or tentatively identified) as gas-phase products in simulation chamber studies of the photooxidation of isoprene (Yu et al., 1995) and 1,3,5-TMB (Smith et al., 1999; Yu et al., 1997) using impingers containing aqueous solutions of PFBHA followed by GC-MS analysis of the oxime derivatives. However, no information on the composition of the particle phase was obtained in these studies.

In the initial experiments performed at PSI, the full range of gas-phase products was identified in both the isoprene and 1,3,5-TMB systems, however, the only products found in the particle phase were glyoxal and methylglyoxal. In order to investigate the molecular composition of the particle phase further, experiments using higher mixing ratios of the parent hydrocarbon were performed at UCC. This 


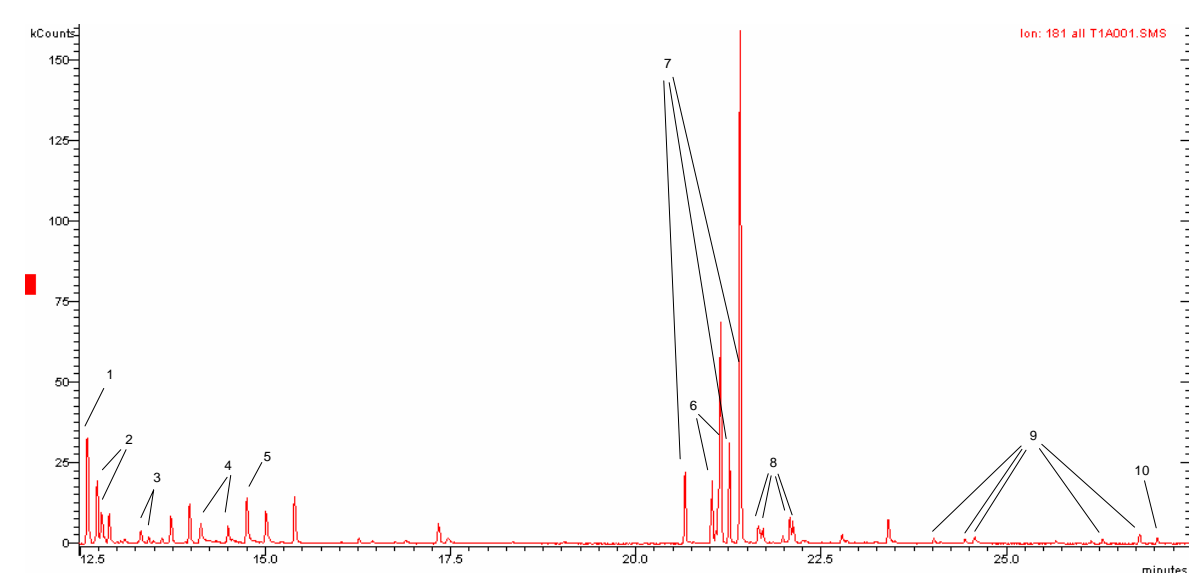

Fig. 7. Reconstructed ion chromatogram $(\mathrm{m} / \mathrm{z}, 181)$ of a denuder extract from the photooxidation of isoprene (experiment ISO_UCC_1). 1: methacrolein 2: methylvinylketone 3: 2-methylbut-3-enal 4: glycolaldehyde 5: hydroxyacetone 6: glyoxal 7: methylglyoxal 8: oxopropanedial 9: 2,3-dioxobutanal 10: oxopropanedial.

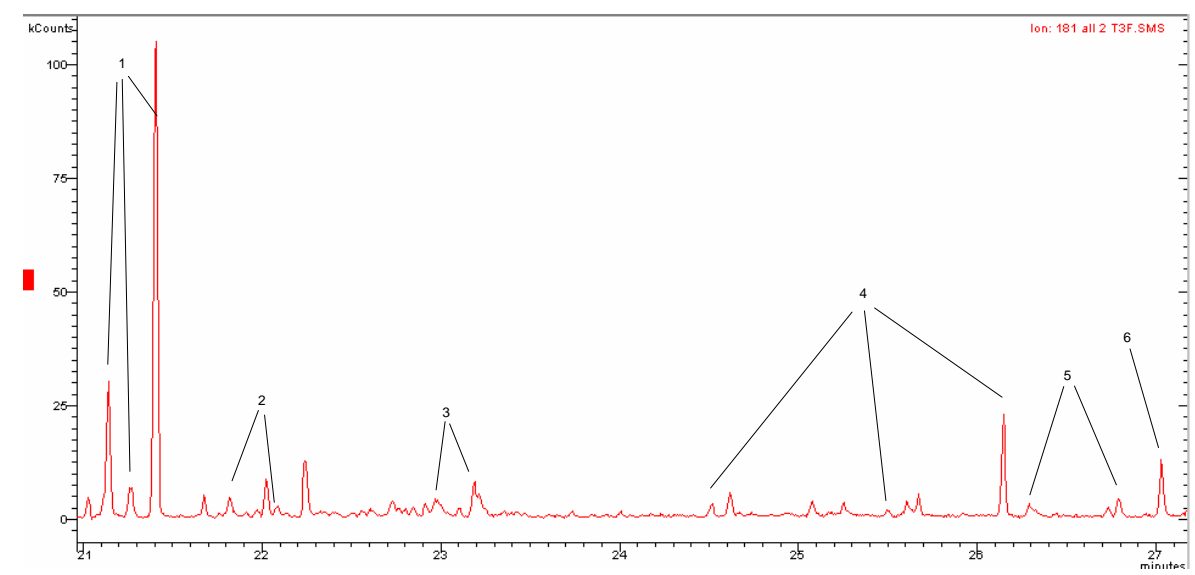

Fig. 8. Reconstructed ion chromatogram $(\mathrm{m} / \mathrm{z}, 181)$ of a filter extract from the photooxidation of 1,3,5-TMB (experiment TMB_UCC_2). 1: methylglyoxal 2: 2,3-dioxobutanal 3: 3-hydroxy-2,4-pentanedione 4: 2-methyl-4-oxo-2-pentenal 5: 2,3-dioxobutanal 6: oxopropanedial.

approach, combined with the increased sensitivity provided by the pre-concentration step and the use of methanol as the extraction solvent, enabled the identification of several other products in the particle phase for both systems. In addition, the use of calibration solutions containing the oximes of the carbonyl products or appropriate surrogate compounds, allowed for estimation of the concentrations of the carbonyls formed. For the isoprene experiments MACR, MVK, glycolaldehyde, hydroxyacetone, glyoxal and methylglyoxal were quantified using their respective standards. The amount of 2-methyl-but-3-enal was determined using the response factor of the valeraldehyde derivative and oxopropanedial and hydroxypropanedial were quantified using 2,3-butanedione as the surrogate compound. For the 1,3,5-TMB experiments 3,5-dimethylbenzaldehyde, glyoxal, and methylglyoxal were quantified using their respective standards. 2,3-dioxobutanal and oxopropanedial were quantified using the response fac- tor of the 2,3-butanedione derivative while 3-hydroxy-2,4pentanedione and 2-methyl-4-oxo-2-pentenal were quantified using 2,5-hexanedione as the surrogate compound. It should be noted that the dicarbonyl compounds can react with PFBHA to produce mono- and di-derivatives. Similarly, the tricarbonyls could produce mono-, di- and tri-derivatives. However, mono-derivatives were not observed for the dicarbonyl and tricarbonyl compounds identified in this study indicating that the derivatizing agent was present in sufficient amounts to completely convert the multifunctional carbonyls at least to the di-derivative form in both denuder and filter extracts. Thus quantification of the dicarbonyls in the gas and particle phases was based on the signal responses observed for their di-derivatives. The tricarbonyls were observed in both the di- and tri-derivatized forms and the response factors for both derivatives were used for quantification purposes. However, the relative amounts of di- and tri-derivatives was 
Table 2. Gas- and particle-phase products observed by GC-MS during the photooxidation of isoprene.

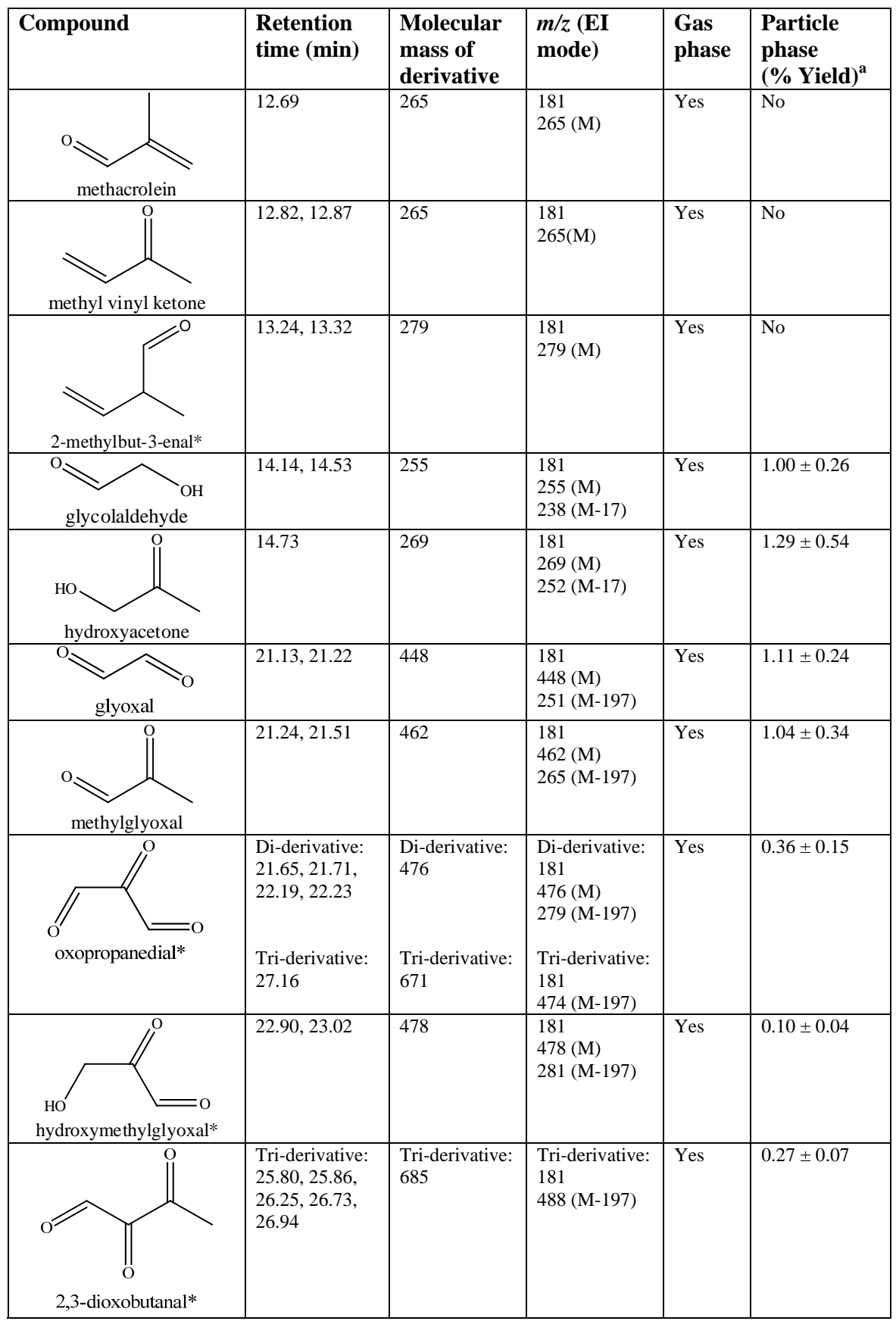

* No standard available. Product tentatively identified on the basis of retention time and mass spectrum.

a Contribution of each carbonyl to the average SOA mass taken from the average of three individual samples taken during experiment ISO_UCC_2. Quoted errors correspond to the relative standard deviation of the three samples.

not constant in every extract, undoubtedly introducing some error in the particle phase yields and experimental partitioning values for oxopropanedial and 2,3-dioxobutanal.
Mechanisms for the formation of the isoprene photooxidation products listed in Table 2 are well established. MACR and MVK are the major primary products formed from addition of $\mathrm{OH}$ to either of the double bonds in isoprene, followed 
Table 3. Gas- and particle-phase products observed by GC-MS during the photooxidation of 1,3,5-TMB.

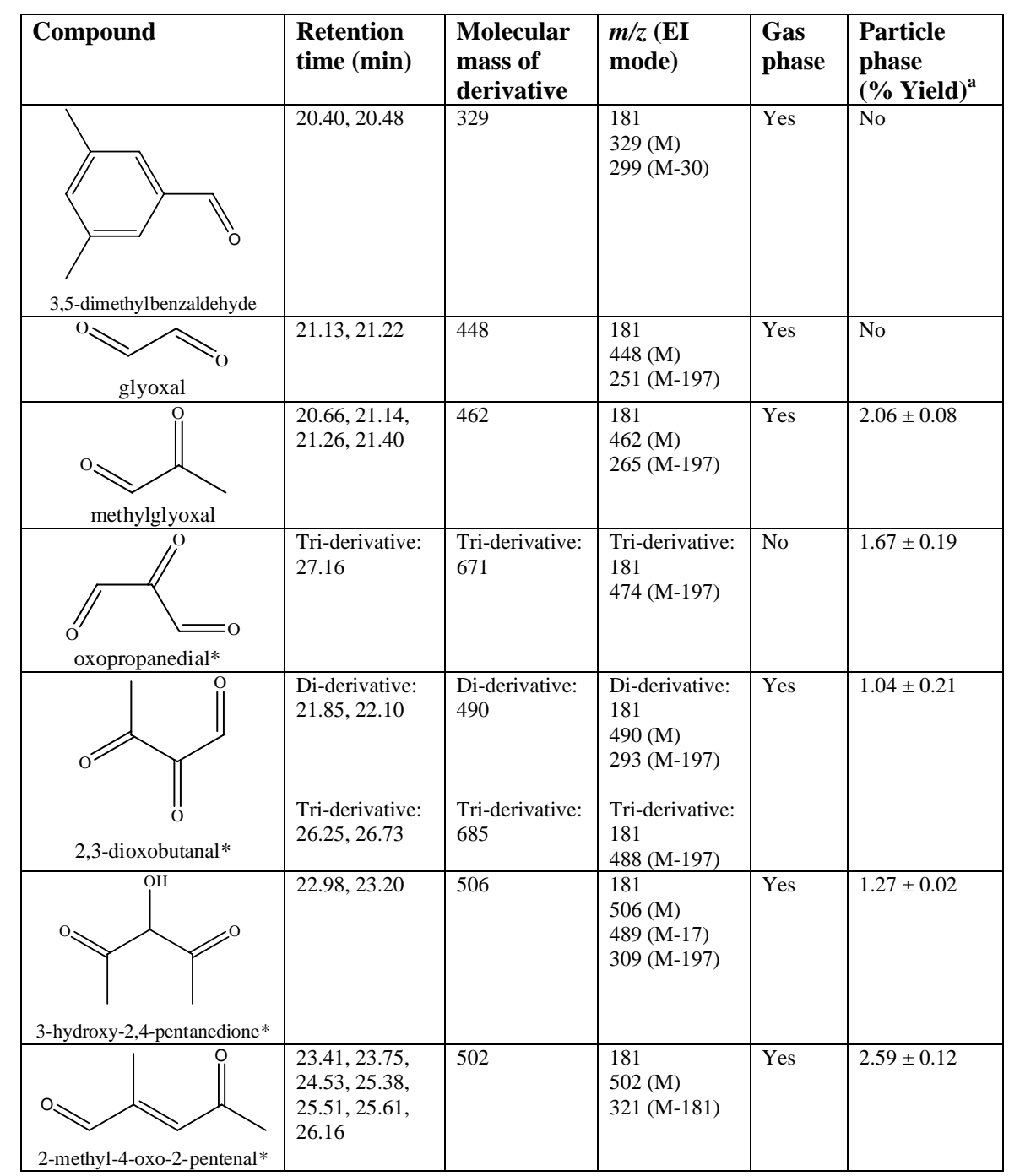

\footnotetext{
* No standard available. Product tentatively identified on the basis of retention time and mass spectrum.

${ }^{a}$ Contribution of each carbonyl to the average SOA mass taken from the average of three individual samples taken during experiment TMB_UCC_2. Quoted errors correspond to the relative standard deviation of the three samples.
}

by oxidation of the corresponding hydroxyalkyl radicals. The unsaturated $\mathrm{C}_{5}$ carbonyl 2-methyl-but-3-enal can also be formed as a primary product in this way although with much lower yields than MACR and MVK (Fan and Zhang, 2004). Further reaction of MACR and MVK with OH leads to the formation of secondary products including glyoxal, methylglyoxal, glycolaldehyde and hydroxyacetone (Spaulding et al., 2003). Yu et al. proposed that hydroxymethylglyoxal is formed through the reaction of $\mathrm{OH}$ with the primary isoprene photooxidation product hydroxybut-3-en-2-one (Yu et al., 1995). Oxopropanedial and 2,3-dioxobutanal are more difficult to explain mechanistically, and although these products (or their corresponding structural isomers) were tenta- tively identified by Yu et al. (1995) they were only observed during ozonolysis experiments (Yu et al., 1995). Interestingly, MACR, MVK and 2-methylbut-3-enal were only observed in the gas-phase, while all the other products were observed in both gas and particle phases. This indicates that SOA formation does not occur from direct condensation of the primary oxidation products, but instead, through further reaction of these species, in agreement with recent studies (Kroll et al., 2006; Ng et al., 2006; Surratt et al., 2006).

Mechanisms for the formation of the 1,3,5-TMB photooxidation products listed in Table 3 are also fairly well established. 3,5-Dimethylbenzaldehyde is formed by $\mathrm{H}$ atom abstraction from one of the methyl groups in the parent 
hydrocarbon and has been observed as its PFBHA derivative in a previous study (Yu et al., 1997). Also observed in that study were the mechanistically expected primary ringopened co-products methylglyoxal and 2-methyl-4-oxo-2pentenal. It was proposed that 3-hydroxy-2,4-pentanedione is a secondary product resulting from further reaction of 2-methyl-4-oxo-2-pentenal and that the tricarbonyls oxopropanedial and 2,3-dioxobutanal are formed through the OH-initiated oxidation of hydroxydicarbonyls (Yu et al., 1997; Edney et al., 2001). Small amounts of glyoxal were detected in the gas phase, but since this dicarbonyl cannot be formed as a primary ring-opened product due to the position of the methyl groups on 1,3,5-TMB, it seems likely that it is formed via secondary reactions, or from oxidation of impurities in the 1,3,5-TMB sample.

The quantification procedure was used to determine yields for the carbonyl compounds detected in the particle phase. The corresponding gas-phase yields were not estimated since denuder-filter sampling was performed only during the latter stages of the photooxidation process when secondary chemistry was dominant. The particle-phase yields shown in Tables 2 and 3 are based on the average of 3 samples. For the isoprene system the identified carbonyls can only account for around $5 \%$ of the SOA mass. A significant amount of the SOA mass (22-34\%) produced from the photooxidation of isoprene under high- $\mathrm{NO}_{\mathrm{x}}$ conditions has been attributed to oligomers and oligoesters arising from oxidation of MACR (Surratt et al., 2006; Szmigielski et al., 2007). A range of other polar organics including tetrols and acids are also present in isoprene SOA (Claeys et al., 2004; Surratt et al., 2006), but the yields of these species are difficult to determine. For the 1,3,5-TMB system the identified carbonyls can account for almost $10 \%$ of the SOA mass. This compares favourably with the work of Hamilton et al. who attributed around $10 \%$ of the mass of toluene SOA to small oxygenated compounds (Hamilton et al., 2005). A dominant fraction of the 1,3,5-TMB SOA mass is also believed to be due to oligomers arising from heterogeneous reaction of oxidation products (Kalberer et al., 2004).

\subsection{Gas/particle partitioning of photooxidation products}

Experimental gas/particle partitioning coefficients, $K_{p, i}$ (experimental), were calculated using the following expression (Odum et al., 1996):

$K_{p, i}($ experimental $)=\frac{C_{p, i}}{C_{g, i} \mathrm{TSP}}$

where $C_{g, i}$ and $C_{p, i}$ are the relative concentrations of each product in the denuder (gas phase) and filter (particle phase) extracts, and TSP is the total suspended particulate concentration or average particle mass concentration $\left(\mu \mathrm{g} \mathrm{m}^{-3}\right)$ measured during the sampling period. For comparison purposes theoretical $K_{p, i}$ values were also calculated using standard absorptive gas/particle partitioning theory (Pankow, 1994a; Pankow, 1994b):

$K_{p, i}($ theoretical $)=\frac{760 R T f_{o m}}{M W_{o m} 10^{6} \zeta_{i} p_{L, i}^{\circ}}$

where $f_{o m}$ is the mass fraction of the TSP that is the absorbing organic material $(\mathrm{om})$ phase, $M W_{o m}$ is the average molecular weight of the absorbing om $\left(\mathrm{g} \mathrm{mol}^{-1}\right)$, $\zeta_{i}$ is the activity coefficient of compound $i$ in the om phase and $p_{L, i}^{o}$ is the vapour pressure (Torr) of the absorbing compound as a liquid, $R$ is the ideal gas constant $\left(8.206 \times 10^{-5} \mathrm{~m}^{3} \mathrm{~atm} \mathrm{~mol}{ }^{-1} \mathrm{~K}^{-1}\right)$ and $T$ is the temperature (K). For experiments performed at PSI, the temperature was maintained at $293 \mathrm{~K}$. At UCC temperatures were in the range 303-305 K during denuder-filter sampling and the exact temperature at the time of sampling was used for calculations of $K_{p, i}$ (theoretical). Liquid vapour pressure values were estimated using the SPARC online calculator (Version 3.1) (Hilal et al., 1995), a group contribution calculation procedure that has been used to estimate vapour pressure values for a range of organic compounds in previous studies (Asher et al., 2002; Barsanti and Pankow, 2004; Barsanti and Pankow, 2005; Barsanti and Pankow, 2006). Since all experiments were performed without inorganic seed aerosol, the value of $f_{\text {om }}$ was assumed to be 1 . Complete knowledge of all the organic constituents in the particle phase is required for determination of the exact value of $\zeta_{i}$. Since the composition of the SOA produced from isoprene and 1,3,5-TMB photooxidation is largely unknown, the value of this parameter is also assumed to be 1, as in previous studies (Johnson et al., 2006; Kamens et al., 1999, Jang and Kamens, 2001). Selection of a suitable value for $M W_{o m}$ is more complicated. Recent simulation chamber experiments have shown that the molecular weight of individual constituents in isoprene (Dommen et al., 2006; Surratt et al., 2006) and 1,3,5-TMB (Kalberer et al., 2004) SOA ranges from 100 to $1000 \mathrm{Da}$ and that the average molecular weight increases considerably with aerosol age due to oligomerization. Unfortunately the average molecular weight was not determined in the experiments reported here due to the lack of available instrumentation. In addition, the denuder-filter samples were collected at different stages during the experiments, and the average molecular weight was therefore expected to vary between samples. As a result, an arbitrary value had to be selected for $M W_{o m}$. In the study of the gas/particle partitioning of the photooxidation products of toluene (Jang and Kamens, 2001) a value of $M W_{\text {om }}=120$ was assumed to be representative of the average molecular weight of the toluene oxidation products present in the particle phase. For similar reasons, a value of 130 was selected by Johnson et al. (2005), for determining $K_{p}$ values for a range of aromatic oxidation products in a large number of SOA formation experiments. In line with these previous studies, a value of $M W_{o m}=120$ was selected for the calculations performed in this work. Although it is accepted that this value may be an underestimate, it does enable a direct comparison 
Table 4. Experimental and theoretical gas/particle partitioning coefficients for isoprene photooxidation products.

\begin{tabular}{llllll}
\hline Experiment & Compound & $n$ & $K_{p, i}($ experimental) & $K_{p, i}$ (theoretical) & $K_{p, i}$ (experimental)/K,$i$ (theoretical) \\
\hline ISO_PSI_2 & Glyoxal & 2 & $(7.34 \pm 0.60) \times 10^{-5}$ & $1.93 \times 10^{-9}$ & 38031 \\
& Methylglyoxal & 2 & $(9.96 \pm 1.78) \times 10^{-6}$ & $4.14 \times 10^{-9}$ & 2405 \\
ISO_UCC_1 & Glyoxal & 3 & $(6.25 \pm 1.33) \times 10^{-5}$ & $9.75 \times 10^{-10}$ & 64102 \\
& Methylglyoxal & 3 & $(1.14 \pm 0.10) \times 10^{-5}$ & $1.95 \times 10^{-9}$ & 5846 \\
& 2,3-dioxobutanal & 3 & $(3.62 \pm 4.77) \times 10^{-4}$ & $8.48 \times 10^{-8}$ & 4271 \\
& Oxopropanedial & 3 & $(2.55 \pm 0.59) \times 10^{-5}$ & $5.58 \times 10^{-8}$ & 456 \\
ISO_UCC_2 & Glyoxal & 3 & $(4.44 \pm 1.46) \times 10^{-5}$ & $9.75 \times 10^{-10}$ & 45538 \\
& Methylglyoxal & 3 & $(6.78 \pm 2.68) \times 10^{-6}$ & $1.95 \times 10^{-9}$ & 3476 \\
& 2,3-dioxobutanal & 3 & $(7.85 \pm 1.76) \times 10^{-5}$ & $8.48 \times 10^{-8}$ & 926 \\
& Oxopropanedial & 3 & $(2.41 \pm 0.97) \times 10^{-5}$ & $5.58 \times 10^{-8}$ & 432 \\
& Glycolaldehyde & 3 & $(2.15 \pm 0.57) \times 10^{-5}$ & $3.60 \times 10^{-7}$ & 59 \\
& Hydroxyacetone & 3 & $(1.48 \pm 0.56) \times 10^{-5}$ & $7.20 \times 10^{-7}$ & 20 \\
& Hydroxymethylglyoxal & 3 & $(2.19 \pm 0.45) \times 10^{-4}$ & $2.49 \times 10^{-6}$ & 88 \\
\hline
\end{tabular}

a Average value based on $n$ measurements during each experiment. Quoted errors correspond to the relative standard deviation.

Table 5. Experimental and theoretical gas/particle partitioning coefficients for 1,3,5-TMB photooxidation products.

\begin{tabular}{llllll}
\hline Experiment & Compound & $n$ & $K_{p, i}(\text { experimental })^{\mathrm{a}}$ & $K_{p, i}$ (theoretical) & $K_{p, i}($ experimental $) / K_{p, i}($ theoretical $)$ \\
\hline TMB_PSI_1 & Methylglyoxal & 1 & $5.89 \times 10^{-5}$ & $4.14 \times 10^{-9}$ & 14227 \\
TMB_PSI_2 & Methylglyoxal & 3 & $(3.94 \pm 3.53) \times 10^{-5}$ & $4.14 \times 10^{-9}$ & 9517 \\
TMB_PSI_3 & Methylglyoxal & 2 & $(2.0 \pm 0.07) \times 10^{-5}$ & $4.14 \times 10^{-9}$ & 4831 \\
TMB_UCC_1 & Methylglyoxal & 3 & $(1.69 \pm 0.90) \times 10^{-5}$ & $1.95 \times 10^{-9}$ & 8667 \\
& 3-hydroxy-2,4-pentanedione & 3 & $(1.09 \pm 0.36) \times 10^{-4}$ & $1.13 \times 10^{-5}$ & 9 \\
& 2-methyl-4-oxo-2-pentenal & 3 & $(1.01 \pm 0.72) \times 10^{-4}$ & $9.32 \times 10^{-7}$ & 108 \\
TMB_UCC_2 & Methylglyoxal & 3 & $(1.22 \pm 0.05) \times 10^{-5}$ & $1.95 \times 10^{-9}$ & 6256 \\
& 2,3-dioxobutanal & 3 & $(2.40 \pm 0.83) \times 10^{-5}$ & $8.48 \times 10^{-8}$ & 283 \\
& 3-hydroxy-2,4-pentanedione & 3 & $(1.40 \pm 0.49) \times 10^{-5}$ & $1.13 \times 10^{-5}$ & 1 \\
& 2-methyl-4-oxo-2-pentenal & 3 & $(1.77 \pm 0.50) \times 10^{-4}$ & $9.32 \times 10^{-7}$ & 190 \\
\hline
\end{tabular}

a Average value based on $n$ measurements during each experiment. Quoted errors correspond to the relative standard deviation.

of our results with previous studies to be made. As discussed below, the observed difference between the theoretical and experimental gas/particle partitioning coefficient values for glyoxal, for example, is about four orders of magnitude, and it is this significant difference we aimed to highlight in this study. Increasing the average molecular weight even to 500 would only reduce the theoretical partitioning coefficient by a factor of 4 and would not change the interpretation and conclusions of this work.

The experimental and theoretical $K_{p, i}$ values (in units of $\mathrm{m}^{3} \mu \mathrm{g}^{-1}$ ) for the isoprene and 1,3,5-TMB photooxidation products are compared in Tables 4 and 5 respectively. The experimental $K_{p, i}$ values observed for glyoxal and methylglyoxal agree relatively well between the two simulation chambers for the isoprene and 1,3,5-TMB systems. The reproducibility of experimental $K_{p, i}$ values is improved for the experiments at UCC due to the pre-concentration of filter extracts and the higher precursor concentrations used. This is the first reported study of gas/particle partitioning in the photooxidation of isoprene and 1,3,5-TMB and a direct comparison with literature values is therefore not possible. However, the values obtained here are broadly in line with the experimental $K_{p, i}$ values determined for a number of different carbonyls in the atmospheric oxidation of toluene (Jang and Kamens, 2001), $\alpha$-pinene (Kamens and Jaoui, 2001) and other biogenic precursors (Yu et al., 1999).

The main feature of the results presented in Tables 4 and 5 is that the experimental $K_{p, i}$ values are much higher than their theoretical counterparts, particularly for the dicarbonyl species glyoxal and methylglyoxal. This provides further evidence to support the view that transfer to the particle phase is not occurring by gas/particle partitioning alone and 
that the heterogeneous reactions of dicarbonyls are important in SOA formation and growth (Kalberer et al., 2004; Kroll et al., 2005b; Liggio et al., 2005b). The reactive uptake of glyoxal into particles has been observed in several previous studies and has been explained by hydration reactions occurring on/in the particle phase leading to larger lowvolatility products (Hastings et al., 2005; Jang et al., 2002; Kroll et al., 2005b; Liggio et al., 2005a). Similar hydration reactions have been observed when evaporating aqueous solutions of glyoxal and methylglyoxal (Loeffler et al., 2006). The reactive uptake of a series of carbonyls and dicarbonyls on ammonium sulfate seed aerosol has been investigated by Kroll et al. (2005b). Glyoxal was the only carbonyl taken up by the inorganic aerosol in the dark and most effectively at a relative humidity of $50 \%$, whilst no significant uptake was observed for methylglyoxal under the same conditions. This is in contrast to the results obtained in this work where both dicarbonyls undergo reactive uptake. It seems that the presence of organic aerosol and/or light significantly improves the reactive uptake of methylglyoxal. Indeed, the OH-initiated oxidation of both glyoxal (Carlton et al., 2007) and methylgloxal (Altieri et al., 2008) in bulk water solutions has been observed to form low-volatility products, including oligomers and acids, in the presence of light. Thus it appears that under the experimental conditions employed here, uptake of methylglyoxal and glyoxal could be followed by $\mathrm{OH}$-initiated oxidation or photolysis in the particle phase to produce oligomers. The formation of oligomers has been previously observed in the photooxidation of both isoprene (Dommen et al., 2006; Surratt et al., 2006; Szmigielski et al., 2007) and 1,3,5-TMB (Kalberer et al., 2004). In the latter case, oligomers attributed to the heterogeneous reactions of methylglyoxal and other carbonyl products, were found to comprise over $50 \%$ of the SOA mass after ageing for $20 \mathrm{~h}$ (Kalberer et al., 2004). Organic acids were also found to account for $20-45 \%$ of the aerosol mass formed and some of these may be produced from the decomposition of larger oligomeric products (Fisseha et al., 2004). Oligomer formation has recently been observed from the atmospheric oxidation of a variety of precursors (Dommen et al., 2006; Hamilton et al., 2006; Kalberer et al., 2004; Tolocka et al., 2004; Zahardis et al., 2006, Hamilton et al., 2008) and it has become clear that heterogeneous and particle phase processes are an important pathway for SOA growth.

The experiments performed in this work are very similar to those previously performed at the PSI chamber where oligomer formation was observed, and as a result the filter samples collected in these experiments are also expected to contain oligomeric material. GC-MS analysis did not reveal the presence of oligomers in extracts of the filter samples, however, there is evidence to indicate that oligomers can revert to their monomeric form in solution. Tests performed at UCC showed that methanol containing PFBHA was found to efficiently dissolve a trimeric glyoxal standard and convert the resulting monomers to oxime derivatives. If glyoxal- or methylglyoxal-based oligomers were present in the particle phase, then reversion to the monomeric form in the extracts would be expected. Indeed, if the oligomerization process is assumed to be reversible, the use of excess PFBHA would be expected to convert the oligomers back to the monomeric species by removing dicarbonyl monomers from the extract as soon as they are formed. However, it cannot be assumed that full reversion to the monomeric form is occurring and therefore the particle phase concentrations can be viewed as a lower limit for the mass that has been taken up through accretion reactions.

The results presented in Tables 4 and 5 show that the deviation from absorptive gas/particle partitioning theory is greatest for glyoxal, methylglyoxal and dialdehydes in general. In fact, with the exception of 3-hydroxy-2,4-pentanedione, all of the dicarbonyls were observed to transfer to the particle phase more effectively than products with a single carbonyl moiety. For example MACR and MVK, although present at relatively high mixing ratios in the gas phase during the isoprene experiments, were not observed in any of the filter extracts. This indicates that the reactive uptake of monofunctional carbonyls by organic aerosol is negligible, even under the conditions employed in these experiments, where the elevated particle concentrations are likely to favour the reactive uptake of carbonyls simply by providing a large surface area for reaction. This observation is consistent with the theoretical calculations performed by Barsanti and Pankow which showed that accretion reactions involving straight-chain aldehydes up to $\mathrm{C}_{10}$ are thermodynamically unfavourable under atmospheric conditions (Barsanti and Pankow, 2004). Indeed, since the amounts of SOA generated in the experiments reported in this work are significantly higher than typical atmospheric organic aerosol loadings, it would be interesting to consider whether the reactive uptake and thus, particle-phase yields of the dicarbonyls would be similar under ambient levels. Unfortunately this could not be investigated experimentally due to a lack of sensitivity in the analytical method. However, Barsanti and Pankow have performed some theoretical calculations on the potential of dicarbonyls to add mass to ambient particulate matter through accretion reactions, using an initial background organic particulate matter concentration of $15 \mu \mathrm{g} \mathrm{m}^{-3}$ (Barsanti and Pankow, 2005). The results indicated that accretion reactions of dicarbonyls, and in particular, glyoxal and methylglyoxal, were expected to have an effect on particulate matter mass loading through hydration/oligomerization and aldol condensation reactions respectively. This indicates that reactive uptake of the dicarbonyls is possible under typical atmospheric organic aerosol loadings. However, it is uncertain how the particle-phase yields of these compounds would differ from those obtained in the presence of elevated particle concentrations. Interestingly, in that study (Barsanti and Pankow, 2005) the contribution of glyoxal and methylglyoxal to the particle phase was predicted to be almost equal, and the experimental $K_{p, i}$ values calculated in this work are 
also on a similar order of magnitude with respect to each other. However, glyoxal does exhibit consistently higher experimental $K_{p, i}$ values than methylglyoxal indicating that the dominating accretion reactions for the dialdehyde may be occurring at a higher rate. Experimental $K_{p, i}$ values for hydroxycarbonyl photooxidation products agreed more closely with their theoretical values based on absorptive partitioning, in particular for 3-hydroxy-2,4-pentanedione, which does not possess an aldehyde functionality and is thus expected to be less reactive. This is in agreement with Barsanti and Pankow who predicted that diketones such as 2,3-butanedione and 2,5-hexanedione would contribute much less to the growth of SOA via accretion reactions because of the lower reactivity of ketones compared to their aldehyde counterparts (Barsanti and Pankow, 2005).

The importance of determining experimental partitioning values is underlined by recent modelling studies of SOA formation from anthropogenic and biogenic precursors in simulation chamber experiments where all gas/particle partitioning coefficients of oxidation products had to be scaled by a species-independent factor of between 5 and 120 to explain the SOA mass formed (Jenkin, 2004; Johnson et al., 2005). A simulation of regional scale SOA formation in the UK required gas/particle partitioning coefficients of oxidation products to be scaled by a factor of 500 (Johnson et al., 2006). The results of this work suggest that different scaling factors, based on the experimental $K_{p, i}$ values, should be used for each compound, or at least each group of compounds.

\section{Conclusions}

Experimental gas/particle partitioning coefficients for a wide range of carbonyl products formed from the photooxidation of isoprene and 1,3,5-TMB were found to deviate to varying extents from their theoretical values based on standard absorptive partitioning theory. Photooxidation products with a single carbonyl moiety were not observed in the particle phase, but dicarbonyls, and in particular, glyoxal and methylglyoxal, exhibited gas/particle partitioning coefficients several orders of magnitude higher than expected theoretically. These findings support the importance of heterogeneous and particle phase chemistry as a pathway for SOA formation and growth during the atmospheric degradation of anthropogenic and biogenic precursors.

Acknowledgements. This work was supported by the European Commission (project EUROCHAMP, contract number RII3CT-2004-505968) and the ACCENT "Access to Infrastructures" programme. The authors would like to thank J. M. S. Lopez for assistance in running the GC-MS samples and the two anonymous reviewers of this manuscript for their helpful comments and suggestions.

Edited by: V. F. McNeill

\section{References}

Altieri, K. E., Seitzinger, S. P., Carlton, A. G., et al.: Oligomers formed through in-cloud methylglyoxal reactions: Chemical composition, properties, and mechanisms investigated by ultrahigh resolution FT-ICR mass spectrometry, Atmos. Environ., 42(7), 1476-1490, 2008.

Asher, W. E., Pankow, J. F., Erdakos, G. B., and Seinfeld, J. H.: Estimating the vapor pressures of multi-functional oxygencontaining organic compounds using group contribution methods, Atmos. Environ., 36(9), 1483-1498, 2002.

Barsanti, K. C. and Pankow, J. F.: Thermodynamics of the formation of atmospheric organic particulate matter by accretion reactions - Part 1: aldehydes and ketones, Atmos. Environ., 38(26), 4371-4382, 2004.

Barsanti, K. C. and Pankow, J. F.: Thermodynamics of the formation of atmospheric organic particulate matter by accretion reactions - Part 2: Dialdehydes, methylglyoxal, and diketones, Atmos. Environ., 39(35), 6597-6607, 2005.

Barsanti, K. C. and Pankow, J. F.: Thermodynamics of the formation of atmospheric organic particulate matter by accretion reactions - Part 3: Carboxylic and dicarboxylic acids, Atmos. Environ., 40(34), 6676-6686, 2006.

Carlton, A. G., Turpin, B. J., Altieri, K. E., et al.: Atmospheric oxalic acid and SOA production from glyoxal: Results of aqueous photooxidation experiments, Atmos. Environ., 41(35), 75887602, 2007.

Carter, W. P. L.: Condensed atmospheric photooxidation mechanisms for isoprene, Atmos. Environ., 30(24), 4275-4290, 1996.

Claeys, M., Graham, B., Vas, G., et al.: Formation of secondary organic aerosols through photooxidation of isoprene, Science, 303(5661), 1173-1176, 2004.

Cocker, D. R., Mader, B. T., Kalberer, M., Flagan, R. C., and Seinfeld, J. H.: The effect of water on gas-particle partitioning of secondary organic aerosol: II. m-xylene and 1,3,5-trimethylbenzene photooxidation systems, Atmos. Environ., 35(35), 6073-6085, 2001.

Dommen, J., Metzger, A., Duplissy, J., et al.: Laboratory observation of oligomers in the aerosol from isoprene/ $\mathrm{NO}_{\mathrm{X}}$ photooxidation, Geophys. Res. Lett., 33(13), L13805, doi:10.1029/2006GL026523, 2006.

Edney, E. O., Driscoll, D. J., Weathers, W. S., et al.: Formation of polyketones in irradiated toluene/propylene/ $\mathrm{NO}_{\mathrm{x}} /$ air mixtures, Aerosol Sci. Technol., 35(6), 998-1008, 2001.

Edney, E. O, Kleindienst, T. E., Jaoui, M., et al.: Formation of 2methyl tetrols and 2-methylglyceric acid in secondary organic aerosol from laboratory irradiated isoprene/ $\mathrm{NO}_{X} / \mathrm{SO}_{2} /$ air mixtures and their detection in ambient $\mathrm{PM}_{2.5}$ samples collected in the eastern United States, Atmos. Environ., 39(29), 5281-5289, 2005.

Fan, J. and Zhang, R.: Atmospheric Oxidation Mechanism of Isoprene, Environ. Chem., 1, 140-149, 2004.

Fisseha, R., Dommen, J., Sax, M., et al.: Identification of organic organic aerosol and the acids in secondary corresponding gas phase from chamber experiments, Anal. Chem., 76(22), 65356540, 2004.

Forstner, H. J. L., Flagan, R. C., and Seinfeld, J. H.: Secondary organic aerosol from the photooxidation of aromatic hydrocarbons: Molecular composition, Environ. Sci. Technol., 31(5), 13451358, 1997. 
Fuzzi, S., Andreae, M. O., Huebert, B. J., et al.: Critical assessment of the current state of scientific knowledge, terminology, and research needs concerning the role of organic aerosols in the atmosphere, climate, and global change, Atmos. Chem. Phys., 6, 2017-2038, 2006,

http://www.atmos-chem-phys.net/6/2017/2006/.

Hamilton, J. F., Lewis, A. C., Reynolds, J. C., Carpenter, L. J., and Lubben, A.: Investigating the composition of organic aerosol resulting from cyclohexene ozonolysis: low molecular weight and heterogeneous reaction products, Atmos. Chem. Phys., 6, 49734984, 2006,

http://www.atmos-chem-phys.net/6/4973/2006/.

Hamilton, J. F., Webb, P. J., Lewis, A. C., and Reviejo, M. M.: Quantifying small molecules in secondary organic aerosol formed during the photo-oxidation of toluene with hydroxyl radicals, Atmos. Environ., 39(38), 7263-7275, 2005.

Hamilton, J. F., Lewis, A. C., Carey, T. J., and Wenger, J. C.: Characterization of Polar Compounds and Oligomers in Secondary Organic Aerosol Using Liquid Chromatography Coupled to Mass Spectrometry, Anal. Chem., 80, 474-480, 2008.

Hastings, W. P., Koehler, C. A., Bailey, E. L., and DeHaan, D. O.: Secondary Organic Aerosol Formation by Glyoxal Hydration and Oligomer Formation: Humidity Effects and Equilibrium Shifts during Analysis, Environ. Sci. Technol., 39(22), 87288735, 2005.

Hilal, S. H., Karickhoff, S. W., and Carreira, L. A.: A rigorous test for SPARC's chemical reactivity models: Estimation of more than 4300 ionization pK(a)s, Quant. Struct.-Act. Rel., 14(4), 348-355, 1995.

Jang, M. S., Czoschke, N. M., Lee, S., and Kamens, R. M.: Heterogeneous atmospheric aerosol production by acid-catalyzed particle-phase reactions, Science, 298(5594), 814-817, 2002.

Jang, M. S. and Kamens, R. M.: Characterization of secondary aerosol from the photooxidation of toluene in the presence of $\mathrm{NO}_{\mathrm{x}}$ and 1-propene, Environ. Sci. Technol., 35(18), 3626-3639, 2001.

Jenkin, M. E.: Modelling the formation and composition of secondary organic aerosol from alpha- and beta-pinene ozonolysis using MCM v3, Atmos. Chem. Phys., 4, 1741-1757, 2004, http://www.atmos-chem-phys.net/4/1741/2004/.

Johnson, D., Jenkin, M. E., Wirtz, K., and Martin-Reviejo, M.: Simulating the formation of secondary organic aerosol from the photooxidation of aromatic hydrocarbons, Environ. Chem., 2(1), 35-48, 2005.

Johnson, D., Utembe, S. R., Jenkin, M. E., et al.: Simulating regional scale secondary organic aerosol formation during the TORCH 2003 campaign in the southern UK, Atmos. Chem. Phys., 6, 403-418, 2006,

http://www.atmos-chem-phys.net/6/403/2006/.

Kalberer, M., Paulsen, D., Sax, M., et al.: Identification of polymers as major components of atmospheric organic aerosols, Science, 303(5664), 1659-1662, 2004.

Kamens, R., Jang, M., Chien, C. J., and Leach, K.: Aerosol formation from the reaction of alpha-pinene and ozone using a gasphase kinetics aerosol partitioning model, Environ. Sci. Technol., 33(9), 1430-1438, 1999.

Kamens, R. M. and Jaoui, M.: Modeling aerosol formation from alpha-pinene plus NOx in the presence of natural sunlight using gas-phase kinetics and gas-particle partitioning theory, Environ.
Sci. Technol., 35(7), 1394-1405, 2001.

Kanakidou, M., Seinfeld, J. H., Pandis, S. N., et al.: Organic aerosol and global climate modelling: a review, Atmos. Chem. Phys., 5, 1053-1123, 2005,

http://www.atmos-chem-phys.net/5/1053/2005/.

Kleindienst, T. E., Edney, E. O., Lewandowski, M., Offenberg, J. H., and Jaoui, M.: Secondary organic carbon and aerosol yields from the irradiations of isoprene and alpha-pinene in the presence of $\mathrm{NO}_{\mathrm{x}}$ and $\mathrm{SO}_{2}$. Environ. Sci. Technol., 40(12), 3807-3812, 2006.

Kroll, J. H., Ng, N. L., Murphy, S. M., Flagan, R. C., and Seinfeld, J. H.: Secondary organic aerosol formation from isoprene photooxidation under high- $\mathrm{NO}_{\mathrm{x}}$ conditions, Geophys. Res. Lett., 32(18), L18808, doi:10.1029/2005GL023637, 2005a.

Kroll, J. H., Ng, N. L., Murphy, S. M., et al.: Chamber studies of secondary organic aerosol growth by reactive uptake of simple carbonyl compounds, J. Geophys. Res.-Atmos., 110, D23207, doi:10.1029/2005JD006004, 2005b.

Kroll, J. H., Ng, N. L., Murphy, S. M., Flagan, R. C., and Seinfeld, J. H.: Secondary organic aerosol formation from isoprene photooxidation, Environ. Sci. Technol., 40(6), 1869-1877, 2006.

Liggio, J., Li, S. M., and McLaren, R.: Heterogeneous reactions of glyoxal on particulate matter: Identification of acetals and sulfate esters, Environ. Sci. Technol., 39(6), 1532-1541, 2005a.

Liggio, J., Li, S. M., and McLaren, R.: Reactive uptake of glyoxal by particulate matter, J. Geophys. Res.-Atmos., 110(D10), D10304, doi:10.1029/2004/JD005113, 2005b.

Loeffler, K. W., Koehler, C. A., Paul, N. M., and DeHaan, D. O.: Oligomer Formation in Evaporating Aqueous Glyoxal and Methyl Glyoxal Solutions, Environ. Sci. Technol., 40(20), 63186323, 2006.

Ng, N. L., Kroll, J. H., Chan, A. W. H., et al.: Secondary organic aerosol formation from m-xylene, toluene, and benzene, Atmos. Chem. Phys., 7(14), 3909-3922, 2007.

Ng, N. L., Kroll, J. H., Keywood, M. D., et al.: Contribution of firstversus second-generation products to secondary organic aerosols formed in the oxidation of biogenic hydrocarbons, Environ. Sci. Technol., 40(7), 2283-2297, 2006.

Odum, J. R., Hoffmann, T., Bowman, F., et al.: Gas/particle partitioning and secondary organic aerosol yields, Environ. Sci. Technol., 30(8), 2580-2585, 1996.

Odum, J. R., Jungkamp, T. P. W., Griffin, R. J., Flagan, R. C., and Seinfeld, J. H.: The atmospheric aerosol-forming potential of whole gasoline vapor, Science, 276(5309), 96-99, 1997.

Pankow, J. F.: An Absorption-Model of Gas-Particle Partitioning of Organic-Compounds in the Atmosphere, Atmos. Environ., 28(2), 185-188, 1994a.

Pankow, J. F.: An Absorption-Model of the Gas Aerosol Partitioning Involved in the Formation of Secondary Organic Aerosol, Atmos. Environ., 28(2), 189-193, 1994b.

Paulsen, D., Dommen, J., Kalberer, M., et al.: Secondary organic aerosol formation by irradiation of 1,3,5-trimethylbenzene- $\mathrm{NO}_{\mathrm{X}}-$ $\mathrm{H}_{2} \mathrm{O}$ in a new reaction chamber for atmospheric chemistry and physics, Environ. Sci. Technol., 39(8), 2668-2678, 2005.

Pöschl, U.: Atmospheric aerosols: Composition, transformation, climate and health effects, Angewandte Chemie-International Edition, 44(46), 7520-7540, 2005.

Smith, D. F., Kleindienst, T. E., and McIver, C. D.: Primary product distributions from the reaction of $\mathrm{OH}$ with $\mathrm{m}$-, $\mathrm{p}$-xylene, 1,2,4- 
and 1,3,5-trimethylbenzene, J. Atmos. Chem., 34(3), 339-364, 1999.

Spaulding, R. S., Schade, G. W., Goldstein, A. H., and Charles, M. J.: Characterization of secondary atmospheric photooxidation products: Evidence for biogenic and anthropogenic sources, J. Geophys. Res.-Atmos., 108(D8), 4247, doi:10.1029/2002JD002478, 2003.

Surratt, J. D., Murphy, S. M., Kroll, J. H., et al.: Chemical composition of secondary organic aerosol formed from the photooxidation of isoprene, J. Phys. Chem. A, 110(31), 9665-9690, 2006.

Szmigielski, R. Surratt, J. D., Vermeylen, R., et al.: Characterization of 2-methylglyceric acid oligomers in secondary organic aerosol formed from the photooxidation of isoprene using trimethylsilylation and gas chromatography/ion trap mass spectrometry, J. Mass Spectrom., 42(1), 101-116, 2007.

Temime, B., Healy, R. M., and Wenger, J. C.: A Denuder-Filter Sampling Technique for the Detection of Gas and Particle Phase Carbonyl Compounds, Environ. Sci. Technol., 41(18), 65146520, 2007.
Tolocka, M. P., Jang, M., Ginter, J. M., et al.: Formation of oligomers in secondary organic aerosol, Environ. Sci. Technol., 38(5), 1428-1434, 2004.

Yu, J. Z., Cocker, D. R., Griffin, R. J., Flagan, R. C., and Seinfeld, J. H.: Gas-phase ozone oxidation of monoterpenes: Gaseous and particulate products, J. Atmos. Chem., 34(2), 207-258, 1999.

Yu, J. Z., Jeffries, H. E., and Lelacheur, R. M.: Identifying Airborne Carbonyl-Compounds in Isoprene Atmospheric Photooxidation Products by Their PFBHA Oximes Using Gas-Chromatography Ion-Trap Mass-Spectrometry, Environ. Sci. Technol., 29(8), 1923-1932, 1995.

Yu, J. Z., Jeffries, H. E., and Sexton, K. G.: Atmospheric photooxidation of alkylbenzenes 1. Carbonyl product analyses, Atmos. Environ., 31(15), 2261-2280, 1997.

Zahardis, J., LaFranchi, B. W., and Petrucci, G. A.: Direct observation of polymerization in the oleic acid-ozone heterogeneous reaction system by photoelectron resonance capture ionization aerosol mass spectrometry, Atmos. Environ., 40(9), 1661-1670, 2006. 